\title{
The Effects of Peptide and Lipid Endocannabinoids on Arthritic Pain at the Spinal Level
}

\author{
Zita Petrovszki, MSc,* Gyula Kovacs, MD,* Csaba Tömböly, MSc, PhD,† György Benedek, MD, DSc,* \\ and Gyongyi Horvath, MD, DSc*
}

\begin{abstract}
BACKGROUND: Hemopressin, a nonapeptide (PVNFKFLSH: HP) derived from the $\alpha$ chain of hemoglobin was shown to interact specifically with brain cannabinoid $\mathrm{CB}_{1}$ receptors. Therefore, it seems to be the only peptide structure with cannabinoid activities. Our goal in this study was to further characterize this peptide and to clarify the antinociceptive potency of the polyunsaturated fatty acid derivates, 2-arachidonoyl-glycerol (2-AG) and anandamide, by investigating their effects on mechanical allodynia at the spinal level.

METHODS: HP was prepared on solid phase by in situ neutralization. After chronic intrathecal catheterization, mechanical hypersensitivity was produced in male Wistar rats by injection of carrageenan $(300 \mu \mathrm{g} / 30 \mu \mathrm{L})$ into the tibiotarsal joint of one of the hind legs. Three hours after carrageenan administration, the ligands were administered intrathecally. The mechanical threshold was assessed using a dynamic aesthesiometer.

RESULTS: 2-AG (1-200 $\mu \mathrm{g})$ and anandamide (10-200 $\mu \mathrm{g})$ decreased carrageenan-induced mechanical allodynia in a dose-dependent manner, whereas HP had no antinociceptive effect in a wide dose range $(0.3-30 \mu \mathrm{g})$. The effect of 2-AG was prevented by the $\mathrm{CB}_{1}$ receptor antagonist AM 251, but not by the $\mathrm{CB}_{2}$ antagonist SSR144528-2. HP (3 and $30 \mu \mathrm{g}$ ) also inhibited the effect of 2-AG. None of the ligands influenced the degree of edema.
\end{abstract}

CONCLUSIONS: HP posttreatment had no effect on mechanical allodynia, whereas spinally injected 2-AG and anandamide were potent drugs. (Anesth Analg 2012;114:1346-52)

$\mathrm{B}$ oth natural and synthetic cannabinoids (CBs) acting on $G$ protein-coupled $C_{1}$ and $C_{2}$ receptors can suppress responses to acute and persistent noxious stimulation. ${ }^{1} \mathrm{CB}_{1}$ receptors are expressed mainly in the central nervous system and in peripheral tissues. ${ }^{2,3} \mathrm{CB}_{2}$ receptors occur predominantly peripherally in immune cells, but recently they have also been found in the brain, spinal cord, and in the dorsal root ganglia (DRG), mainly on glial cells. ${ }^{1,4-7}$ A major limitation to the use of CB for therapeutic purposes is the profile of side effects (such as dysphoria) and potential abuse. An alternative approach, which may prevent such side effects, is to influence the endogenous $\mathrm{CB}$ system.

Hemopressin (HP), a nonapeptide (H-PVNFKFLSH-OH), is a product of the hemoglobin $\alpha$ chain, discovered in rat brain and so named because it can cause small decreases in arterial blood pressure. ${ }^{8,9}$ A number of in vitro studies show that $\mathrm{HP}$ acts as a $\mathrm{CB}_{1}$ receptor inverse agonist, and it can act on both peripheral and central pain pathways in vivo. ${ }^{10-12}$ These studies showed that HP pretreatment caused antinociceptive effects at systemic, local, and spinal

From the *Department of Physiology, Faculty of Medicine, Szeged; and tInstitute of Biochemistry, Biological Research Center, Hungarian Academy of Sciences, Szeged, Hungary.

Accepted for publication January 12, 2012.

Supported by a grant of TAMOP 4.2.2.-08/01-2008-0002 and Hungarian Research Grants (OTKA: K83810, K77783).

The authors declare no conflicts of interest.

Gyula Kovacs, MD, is currently affiliated with the Department of Orthopedics, Jozsef Hollos County Hospital, Kecskemet, Hungary.

Reprints will not be available from the authors.

Address correspondence to Gyongyi Horvath, MD, DSc, Department of Physiology, Faculty of Medicine, University of Szeged, PO Box 427, H-6701, Szeged, Hungary. Address e-mail to horvath.gyongyi@med.u-szeged.hu.

Copyright (C) 2012 International Anesthesia Research Society

DOI: 10.1213/ANE.0b013e31824c4eeb levels. The authors proposed that after $\mathrm{CB}_{1}$ blockade by the inverse agonist $\mathrm{HP}$, the released endocannabinoids might induce antinociception by interfering with other pain transmission mechanisms. ${ }^{12}$ Our primary goal was to synthesize this peptide and to determine the effects of HP posttreatment on the mechanical pain threshold in a joint inflammation model at the spinal level.

The family of endocannabinoids comprises several polyunsaturated fatty acid derivates, such as $\mathrm{N}$-arachidonoylethanolamine (anandamide) and 2arachidonoyl-glycerol (2-AG). ${ }^{13,14}$ Anandamide was characterized as an endogenous eicosanoid with moderate affinity for the $\mathrm{CB}_{1}$ and $\mathrm{CB}_{2}$ receptors. ${ }^{13}$ However, anandamide activates other receptors as well, including the capsaicin-sensitive transient receptor potential vanilloid 1 channels (TRPV1), and some of its effects (such as antinociception) may be at least partially attributed to TRPV1 activation. ${ }^{15-23}$ As for the lipid derivative 2-AG, it is a full agonist of $\mathrm{CB}_{1}$ and $\mathrm{CB}_{2}$ receptors with no direct binding to the TRPV1 receptor. ${ }^{14}$ Some studies have investigated its antinociceptive potency at systemic and peripheral levels. ${ }^{14,24-27}$ However, there are no data either about the effect of 2-AG after intrathecal administration, or about the effect of anandamide on mechanical allodynia at the spinal level. Therefore, our secondary goal was to determine the antinociceptive potency of 2-AG and anandamide in the above-mentioned circumstances. Finally, we also sought to determine the consequences of the administration of synthetic $C_{1}$ and $C_{2}$ antagonists and $H P$ on the effects of 2-AG.

\section{METHODS}

\section{Drugs}

Amino acid derivatives and resins were purchased from Bachem AG (Bubendorf, Switzerland) and Sigma (St. Louis, 
$\mathrm{MO})$; coupling agents were from Calbiochem-Novabiochem AG (Läufelingen, Switzerland). All other chemicals and solvents were of analytical grade from commercial sources.

The following drugs were administered in the in vivo experiments: $\lambda$-carrageenan (Sigma-Aldrich Ltd., Budapest, Hungary), 2-AG (Tocris Bioscience, Bristol, UK), anandamide (Sigma-Aldrich Ltd.), AM $251\left(\mathrm{CB}_{1}\right.$ receptor antagonist; Tocris Bioscience), and SSR144528-2 (SSR) ( $\mathrm{CB}_{2}$ receptor antagonist; a generous gift from Sanofi Aventis, Paris, France).

Carrageenan and HP were dissolved in physiological saline. Anandamide and 2-AG were dissolved in ethanol: Tween $=2: 1$, respectively. Stock solutions were diluted with saline to a final ethanol concentration of 10\%. AM 251 and SSR were dissolved in dimethyl sulfoxide (SigmaAldrich, Ltd.) and ethanol and it was further diluted with distilled water. The concentration of dimethyl sulfoxide and ethanol was $15 \%$ and $9 \%$, respectively. Intrathecally administered drugs were injected over 120 seconds in a volume of $10 \mu \mathrm{L}$, followed by a $10-\mu \mathrm{L}$ flush of physiological saline.

\section{In Vitro Experiments: Synthesis of HP}

HP (H-Pro-Val-Asn-Phe-Lys-Phe-Leu-Ser-His-OH) was prepared by in situ neutralization solid-phase peptide synthesis on Boc-His(Tos)-PAM (0.46 mmol/g loading) resin using $N$-[(1H-benzotriazol-1-yl)(dimethylamino)methylene]- $N$ methylmethanaminium tetrafluoroborate $N$-oxide (TBTU) as coupling agent. Completion of the couplings was tested by the Kaiser test. Removal of the orthogonal protecting groups and cleavage of the peptide from the resin were achieved by anhydrous hydrogen fluoride $(10 \mathrm{~mL} / \mathrm{g}$ peptide-resin $)$ in the presence of $10 \%(\mathrm{v} / \mathrm{v})$ anisole and $10 \%(\mathrm{v} / \mathrm{v})$ dimethyl sulfide at $0^{\circ} \mathrm{C}$. The crude peptide was precipitated with diethyl ether from the trifluoroacetic acid (TFA) solution and then purified by reversed phase high-performance liquid chromatography (RP-HPLC) on a Vydac 218TP1010 semipreparative column $(250 \times 10 \mathrm{~mm}, 12 \mu \mathrm{m}$; Grace, Deerfield, IL) with a gradient of acetonitrile $(0.08 \% \mathrm{TFA})$ in water $(0.1 \% \mathrm{TFA})$. The purity of the peptide was examined by analytical RP-HPLC and its molecular weight was confirmed by electrospray ionization mass spectrometry.

\section{In Vivo Experiments}

\section{Intrathecal Catheterization}

The animal surgery and testing procedures were approved by the Institutional Animal Care Committee of the University of Szeged, Faculty of Medicine. Male Wistar rats (weight, $232 \pm 2.0 \mathrm{~g}$ ) were anesthetized with a mixture of ketamine hydrochloride and xylazine $(72$ and $8 \mathrm{mg} / \mathrm{kg}$ intraperitoneally, respectively). An intrathecal catheter (PE-10 tubing, inside diameter $0.28 \mathrm{~mm}$; outside diameter 0.61 mm; Intramedic, Clay Adams, Becton Dickinson, Parsippany, NJ) was inserted through the cisterna magna and passed $8.5 \mathrm{~cm}$ caudally into the subarachnoid space ${ }^{28}$ to place the catheter tip between the vertebrae T12 and L2, corresponding to the spinal segments that innervate the hindpaws. ${ }^{29}$ After the surgery, the rats were housed separately, and they had free access to food and water. Rats exhibiting postoperative neurologic deficits (approximately $10 \%$ ) or those that did not show paralysis of one of the hindpaws after $100 \mu \mathrm{g}$ lidocaine were excluded. ${ }^{29}$ The rats were allowed to recover for at least 4 days before the testing and they were assigned randomly to the treatment groups (6-15 rats per group). The observer was blinded to the treatment administered in all cases.

\section{Carrageenan-Induced Inflammation}

Inflammation was elicited by injecting carrageenan (300 $\mu \mathrm{g} / 30 \mu \mathrm{L}$ ) into one of the tibiotarsal joints (on the paralyzed side during lidocaine administration). ${ }^{29,30}$ Carrageenan was given to gently restrained conscious animals, using a 27-gauge needle, without anesthesia, so as to exclude any drug interaction. These injections did not elicit any sign of major distress. This way hyperalgesia was induced, peaking at 2 to 3 hours after the injection. To determine the changes in the size of the inflamed joint, we measured the anteroposterior and mediolateral diameter of the paw at the level of the ankle joint with a digital caliper. The cross-sectional area was calculated with the formula $\mathrm{a} \times \mathrm{b} \times \pi$, where $\mathrm{a}$ and $\mathrm{b}$ signify the radius in the 2 aspects.

\section{Behavioral Nociceptive Testing}

The threshold of withdrawal from mechanical stimulation to the plantar aspect of the hindpaws was assessed using the Dynamic Aesthesiometer apparatus (mod-37450; Ugo Basile, Comerio, Italy), which consists of an elevated wire mesh platform to allow access to the ventral surface of the hindpaws. Before baseline testing, each rat was habituated to the testing box for at least 20 minutes. A steel rod (diameter $0.5 \mathrm{~mm}$ ) was pushed against the hindpaw with ascending force. The force ranged from 0 to $50 \mathrm{~g}$ over an 8 -second period. When the animal withdrew the hindpaw, the mechanical stimulus was automatically stopped, and the force at which the animal withdrew the paw was recorded at $0.1-\mathrm{g}$ correctness.

\section{Experimental Protocol}

After baseline determination of joint diameter and mechanical paw withdrawal threshold (precarrageenan baseline value at -180 minutes), carrageenan was injected. These measurements were performed again 3 hours after carrageenan injection (postcarrageenan baseline values at 0 minutes). After postcarrageenan baseline determination, HP $(0.3-30 \mu \mathrm{g}), 2-A G(1-200 \mu \mathrm{g})$, or anandamide (10-200 $\mu \mathrm{g})$ was given intrathecally, and mechanical sensitivity was defined at 10, 20, 30, 45, 60, 75, 90, and 105 minutes postadministration. The control group received physiological saline (vehicle of HP) or vehicle of 2-AG/anandamide (see Methods). Because vehicle-treated groups did not differ from the saline-treated, we merged the data of these animals.

To determine the involvement of $\mathrm{CB}_{1}$ and $\mathrm{CB}_{2}$ receptors in the effects of 2-AG, separate groups of animals were pretreated with AM 251 (antagonist of $\mathrm{CB}_{1}$ receptors, 10 $\mu \mathrm{g}$ ) or SSR (antagonist of $\mathrm{CB}_{2}$ receptors, $15 \mu \mathrm{g}$ ) 20 minutes before 200- $\mu \mathrm{g}$ 2-AG injection. The control group was injected with vehicles of 2-AG and CB antagonists. To investigate the potential antagonistic effects of $\mathrm{HP}$ on the 2-AG-induced antinociception, we coadministered 3 or 30 $\mu \mathrm{g}$ HP with $200 \mu \mathrm{g} 2-\mathrm{AG}$.

At the end of the experiment, the joint diameters were measured again. As for the behavioral changes, we did not 
observe any sign of altered behavior (i.e., immobility, flaccidity, excitation, or motor weakness), except for when 100 or $200 \mu \mathrm{g}$ of anandamide was administered. Anandamide in these high doses caused temporary (during the injection) vocalization and excitation, suggesting a paininducing potential of anandamide. ${ }^{23,25}$ Animal suffering and the number of animals per group were kept at a minimum.

\section{Statistical Analysis}

Data are presented as means \pm SEM. Data sets were examined by repeated measures analysis of variance (ANOVA). Post hoc comparisons were performed with the Fisher LSD test. A $P$ value $<0.05$ was considered significant. Data analyses were performed with the STATISTICA for Windows software (Statistica Inc., Tulsa, OK).

\section{RESULTS}

\section{In Vitro Experiments: Synthesis}

HP was prepared by manual solid-phase peptide synthesis using in situ neutralization Boc chemistry. The peptide was purified to homogeneity by semipreparative RP-HPLC and its molecular weight was confirmed by mass spectrometry. To investigate the hydrolytic stability of the peptide, it was dissolved in phosphate-buffered saline and the resulting solutions were incubated at ambient temperature for 10 hours. During the incubation period, samples were taken and analyzed by RP-HPLC. HP was found to be stable, because there were no impurities or hydrolytic fragments detected by RP-HPLC.

\section{In Vivo Experiments Joint Edema}

Three hours after the injection of carrageenan into the ankle, there was a significant $(P<0.01)$ increase in joint cross-sectional area compared with preinjection control levels (from $36 \pm 0.1 \mathrm{~mm}^{2}$ to $73 \pm 0.5 \mathrm{~mm}^{2}$ ). This conspicuous increase in joint size was a result of edema formation, confirming that carrageenan treatment resulted in an inflammatory reaction. None of the treatments influenced the degree of edema; the cross-section of the ankle was $72 \pm 0.5$ $\mathrm{mm}^{2}$ at the end of the experiments, which did not differ from the postcarrageenan baseline value (to $73 \pm 0.5 \mathrm{~mm}^{2}$ ).

\section{Mechanosensitivity}

The basal mechanical withdrawal threshold was $45 \pm 0.4 \mathrm{~g}$, and carrageenan did cause a significant decrease in paw withdrawal threshold on the inflamed side $(10 \pm 0.3 \mathrm{~g})$, but it did not have a significant influence on the noninflamed side. None of the treatments changed the mechanosensitivity on the normal side; therefore, results were analyzed only on the inflamed paws.

HP caused neither a significant antiallodynic effect compared with the control group, nor were any motor impairments observed in this wide dose range $(0.3-30 \mu \mathrm{g})$ (Fig. 1A).

2-AG by itself produced a dose-dependent antiallodynic effect, which developed gradually, and reached a maximum between 45 and 60 minutes (Fig. 1B). ANOVA with repeated measures showed significant effects of treatment $\left(F_{4,48}=4.7, P<0.005\right)$ and time $\left(F_{9432}=94.3, P<0.001\right)$.
Thus, $1 \mu \mathrm{g}$ 2-AG was ineffective, whereas $200 \mu \mathrm{g}$ caused a prolonged antinociceptive effect.

Anandamide elicited a dose-dependent antinociceptive effect, which reached maximum at approximately 20 minutes after administration (Fig. 1C). ANOVA with repeated measures showed significant effects of treatment $\left(F_{4,47}=\right.$ 5.2, $P<0.005)$, time $\left(F_{9423}=68.5, P<0.001\right)$, and interaction $\left(F_{36,423}=1.9, P<0.005\right)$. Thus, $10 \mu \mathrm{g}$ anandamide was ineffective, whereas $200 \mu \mathrm{g}$ caused a prolonged effect.

Regarding the effects of antagonists AM 251 and SSR at $C B_{1}$ and $C_{2}$ receptors, respectively, none of these substances alone influenced the pain threshold (Fig. 2, A and B). AM 251 pretreatment antagonized the antiallodynic effect of 2-AG $(200 \mu \mathrm{g})$, whereas SSR did not influence it (Fig. 2, A and B). Cotreatment of $3 \mu \mathrm{g}$ or $30 \mu \mathrm{g}$ HP with 200 $\mu \mathrm{g} 2-\mathrm{AG}$ significantly decreased the antinociceptive effect of 2-AG (Fig. 2, C and D).

\section{DISCUSSION}

Our results showed that $\mathrm{HP}$ is a stable peptide, and its intrathecal administration after induction of joint inflammation does not influence mechanical allodynia in a wide dose range, but it does inhibit the antinociceptive effects of 2-AG.

Only a few studies investigated the in vivo and in vitro characteristics of HP. Conformation-state sensitive antibodies were used for the investigation of binding characteristics of HP to different opioid, CB, adrenergic, bradykinin, and angiotensin receptors in cell lines and striatum. ${ }^{12}$ It has been found that $\mathrm{HP}$ is an inverse agonist of $\mathrm{CB}_{1}$ receptors, thus $\mathrm{HP}$ is able to block the constitutive activity of $\mathrm{CB}_{1}$ but not $\mathrm{CB}_{2}$ receptors. ${ }^{12} \mathrm{~A}$ recent study demonstrated that $\mathrm{HP}$ can antagonize $\mathrm{CB}_{1}$ agonist-induced internalization of the $\mathrm{CB}_{1}$ receptors in vitro. ${ }^{10}$ As for the few earlier in vivo results, it was observed that $\mathrm{HP}$ causes hypotension by activation of nitric oxide release, ${ }^{8,9,31}$ and it induces hypophagia only in mice with functional $\mathrm{CB}_{1}$ receptors. ${ }^{10}$

Regarding the antinociceptive potency of $\mathrm{HP}$, Dale et al. ${ }^{11}$ found that intraplantarly administered $\mathrm{HP}(0.1-20 \mu \mathrm{g})$ did not affect the paw pressure threshold in the noninflamed paws, but cotreatment with carrageenan or bradykinin significantly decreased the development of mechanical allodynia, as measured with the paw pressure test, and the effect was not inhibited by an opioid antagonist. Because the contralaterally administered HP was also effective in this respect, the data suggest systemic effects of the ligand. Orally (50 or 100 $\mu \mathrm{g} / \mathrm{kg}$ ) or intrathecally ( 0.5 or $5 \mu \mathrm{g})$ administered HP pretreatments were also effective in the same test. ${ }^{12}$ Intraperitoneally administered HP (50 or $500 \mu \mathrm{g} / \mathrm{kg}$ ) exhibited marked antinociceptive potency in the acetic acid-induced visceral nociception model. This high dose of HP did not impair motor activity or alter pentobarbital-induced sleeping time, indicating the absence of unwanted sedative or motor side effects. Unfortunately, we did not observe similar antinociceptive effects in our model. It is possible that the controversial results might be attributable to differences in the timing of administration. That is, we applied HP after the mechanical allodynia had been established 

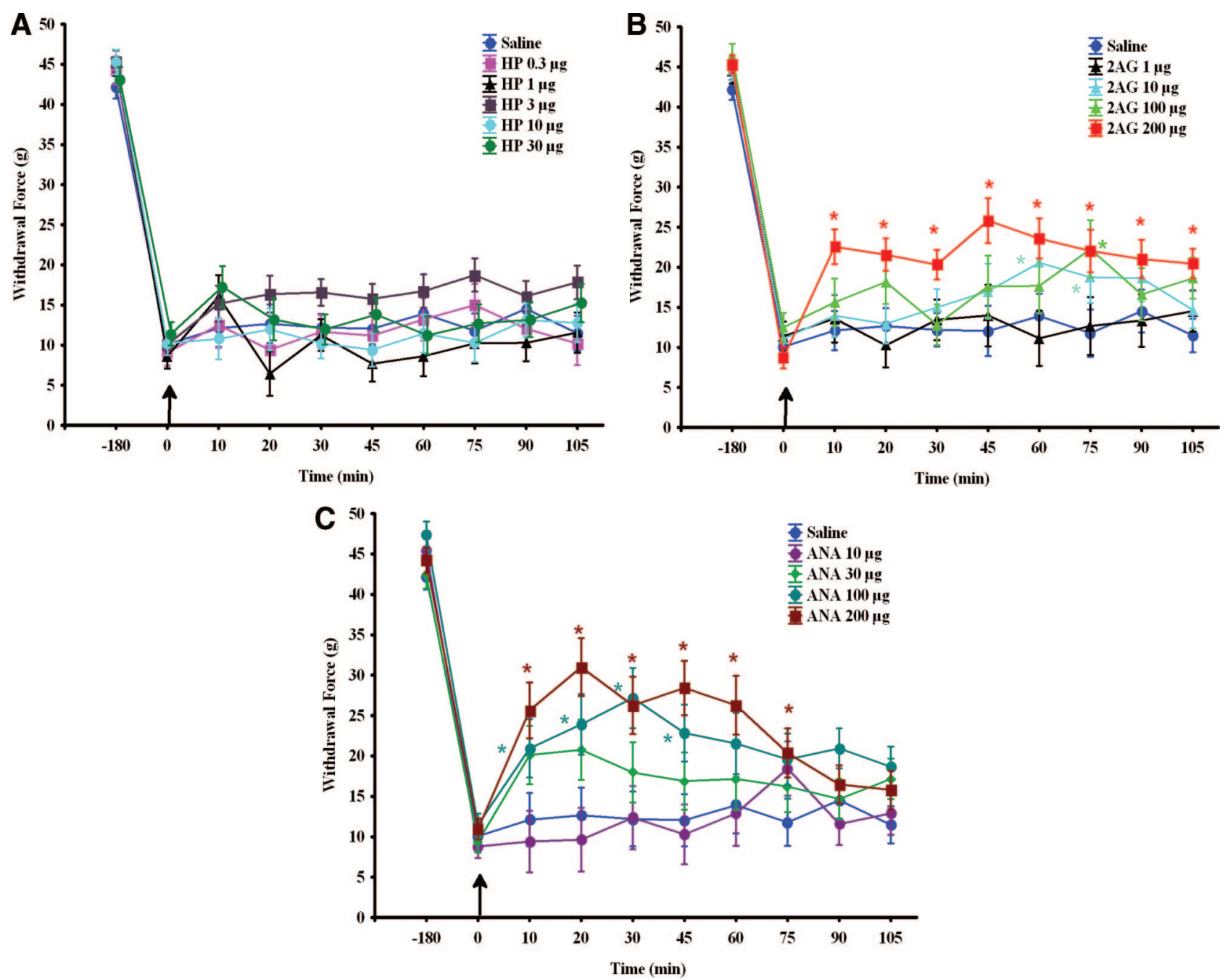

Figure 1. Time course and dose-dependent effects of hemopressin (HP) (A), 2-arachidonoyl-glycerol (2-AG) (B), and anandamide (ANA) (C) on the inflamed side. The arrows show the injections. Each point signifies the mean \pm SEM of the results. $*$ Significant $(P<0.05)$ difference compared with the vehicle-treated group.

(posttreatment), whereas earlier studies prevented the development of the hyperalgesia (pretreatment). Furthermore, there were differences regarding either the applied pain test (paw pressure versus von Frey) or the site of administration of carrageenan (intraplantar versus intrajoint administration). In agreement with our results, the latest evidence suggests inefficacy of HP at the spinal level in an acute heat pain test and in a neuropathic pain model. ${ }^{32,33}$ As for the HP pretreatment before formalin administration, a low dose of HP $(3 \mu \mathrm{g})$ decreased, but a higher dose $(10 \mu \mathrm{g})$ enhanced the formalin-induced nocifensive behavior. The authors observed the inefficacy of HP as an antagonist after CB1 receptor activation. This is in contrast with our results, because $\mathrm{HP}$, similarly to the synthetic $\mathrm{CB}_{1}$ antagonist, antagonized the antinociceptive effect of 2-AG in our study. We suppose that the differences in the pain models and the applied CB ligand (WIN 55,212-2 versus 2-AG) might be the explanation for the different results.

Spinally administered anandamide and 2-AG significantly decreased mechanical inflammatory pain sensitivity.
The use of $\mathrm{CB}$ for the management of a wide range of painful disorders has been well documented at spinal, supraspinal, and peripheral levels, ${ }^{1,4,34}$ whereas endogenous ligand data are scarce, especially at the spinal level. Earlier studies showed that intrathecal anandamide decreased acute heat pain sensitivity (in hotplate and tail-flick tests) and carrageenan-induced thermal hyperalgesia in rodents, and that both the $C_{1}$ and TRPV1 receptors have a role in these effects. $^{23,35,36}$ To our knowledge, we are the first to offer evidence to suggest that anandamide inhibits mechanical allodynia at the spinal level as well. Because several systems may be influenced by anandamide (e.g., CB, TRPV1, glycine, and serotonin-3 receptors), their net effect may be observed under these circumstances. ${ }^{15,16,37-40}$ Because the high dose of anandamide caused temporary pain, the desensitization of TRPV1 receptors can also be involved in its antinociceptive effect, as suggested earlier. ${ }^{18,23}$ Therefore, it is possible that alterations in the release of excitatory and inhibitory transmitters can modify the activation of projection neurons, either presynaptically from primary sensory neurons or postsynaptically from interneurons, or both. 
A
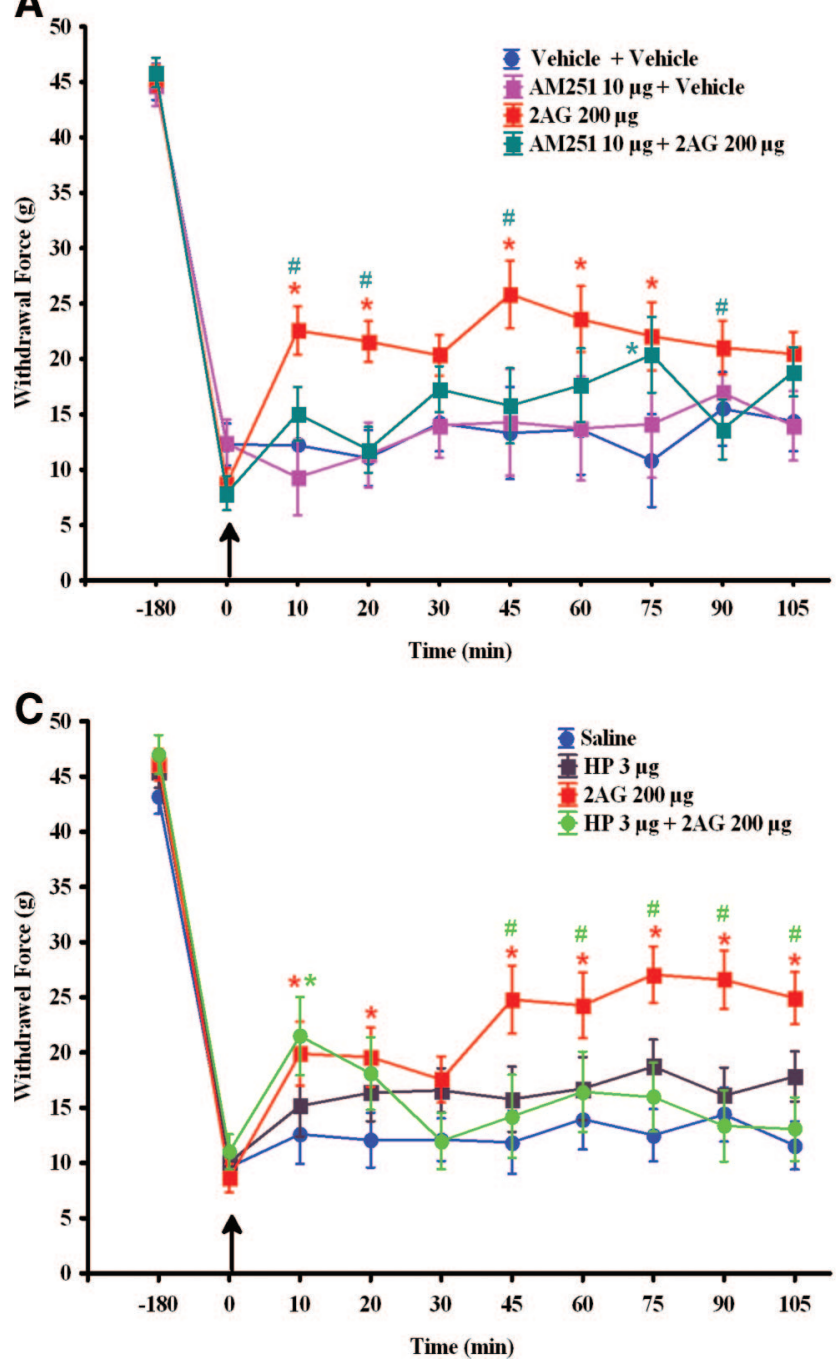

B
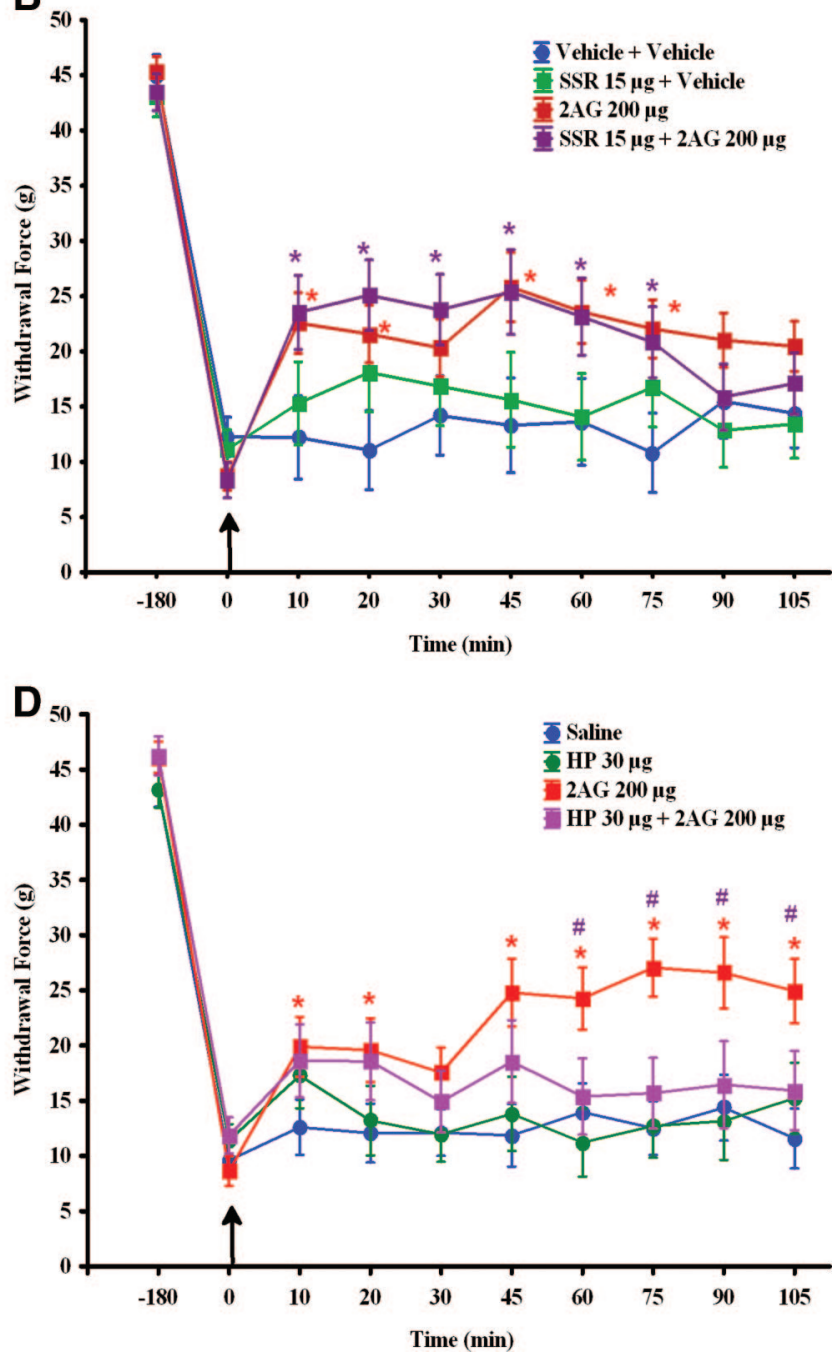

Figure 2. The effects of AM 251 (A), SSR (B), and hemopressin (HP) (C and D) on the antinociceptive effects of $200 \mu g$ 2-arachidonoy-glycerol (2-AG). The arrows show the injections. Each point signifies the mean \pm SEM. *Significant $(P<0.05)$ difference compared with the vehicle-treated group. \#Significant differences between the 2-AG and 2-AG + antagonist/HP-treated groups.

2-AG, similarly to anandamide, reduced allodynia in the carrageenan-induced arthritis model, and its antinociceptive effect was inhibited by a $\mathrm{CB}_{1}$ antagonist, whereas it was not influenced by a $\mathrm{CB}_{2}$ antagonist. This is the most abundant endogenous $\mathrm{CB}$, and its concentration in the brain is 50 to 500 times higher than that of anandamide. It has also been identified peripherally. ${ }^{2,41} 2-\mathrm{AG}$ is a full agonist for $\mathrm{CB}_{1}$ and $\mathrm{CB}_{2}$ receptors with no direct binding to the TRPV1 receptor. ${ }^{14}$ It is also a substrate for cyclooxygenase-2, and 2-AG is capable of suppressing an increase of cyclooxygenase- 2 expression by activating the $\mathrm{CB}_{1}$ receptors. ${ }^{42,43}$ There is only little evidence to support the antinociceptive potency of 2-AG. Endogenous 2-AG has been implicated as a major transmitter involved in endocannabinoid-mediated stress-induced analgesia. ${ }^{44,45}$ Thus 2-AG, but not anandamide, is mobilized in the lumbar spinal cord after exposure to footshock stress, and spinal 2-AG levels show marked correlation with stressinduced antinociception. ${ }^{45,46}$ Additionally, intrathecal administration of an inhibitor of the 2-AG hydrolyzing enzyme, monoacylglycerol lipase, enhances stress-induced antinociception in a $\mathrm{CB}_{1}$-dependent manner. ${ }^{45}$ In systemic administration to mice, 2 -AG (50\% effective dose $=12.5$ $\mathrm{mg} / \mathrm{kg}$ ) caused antinociception in acute pain tests, immobility, reduction of spontaneous activity, and decrease of rectal temperature. ${ }^{14,24}$ Topical administration of 2-AG also decreased the nocifensive behavior in a formalin test, decreased mechanical allodynia and thermal hyperalgesia in a neuropathic pain model, and it was also effective in the alleviation of inflammatory joint pain. ${ }^{25-27}$ The local antinociceptive effects of 2-AG were prevented by $\mathrm{CB}_{1}$ and/or $\mathrm{CB}_{2}$ antagonists. ${ }^{25-27}$ As far as the spinal level is concerned, we are the first to show its antinociceptive potency, and that the effect is reversed by a $\mathrm{CB}_{1}$ antagonist drug (but not by a $\mathrm{CB}_{2}$ antagonist), suggesting that the antiallodynic effect of 2-AG is mainly attributable to the activation of $\mathrm{CB}_{1}$ receptors at the spinal level. $\mathrm{CB}_{1}$ receptors, the molecular targets of $2-A G$, are located on primary afferent fiber endings and/or on intrinsic interneurons in the dorsal horn of the spinal cord ${ }^{47,48}$; therefore, their activation could have led to the observed antinociception. 
It is important to consider that these ligands can influence the activity of neurons in DRG too, because the CB receptors can be found on DRG neurons, ${ }^{49,50}$ and it has been shown that intrathecal injection of sodium fluorescein results in massive staining in the DRG both in the cellular and fiber portions. ${ }^{51}$ As for the ineffectivity of $C_{1}$ and $C_{2}$ antagonists alone on inflamed and noninflamed sides, a number of scenarios may be suggested. First, it might be supposed that the mechanical pain threshold after carrageenan administration (approximately 10-15 g) is a very low value, which could not be further decreased by an antagonist. However, the threshold on the normal side did not change either; therefore, this is not likely. Another possibility is that the endogenously released CBs have no significant inhibitory effect on the mechanical threshold in inflammatory circumstances, either on the normal or on the inflamed side. Similar results were found in a bone cancerinduced pain model ${ }^{52}$; however, other studies have shown that intrathecal injection of $\mathrm{CB}_{1}$ receptor antagonists can evoke nociceptive responses. ${ }^{53,54}$ It is assumed that the differences in the pain models can lead to these controversial findings. However, the level of the released endogenous CBs was not determined in our study; therefore, it cannot be decided whether this is attributable to lack of production or lack of effect of endogenous CB agonists.

In conclusion, we found that HP was not capable of influencing the established mechanical allodynia in a model of arthritic pain, but inhibited the antinociceptive effects of 2-AG at the spinal level. Furthermore, these findings are the first to demonstrate the antinociceptive potency of 2-AG at the spinal level, and the effect of anandamide on mechanical allodynia in an arthritic pain model.

\section{DISCLOSURES}

Name: Zita Petrovszki, MSc.

Contribution: This author helped conduct the study, analyze the data, and write the manuscript.

Attestation: Zita Petrovszki has seen the original study data, reviewed the analysis of the data, and approved the final manuscript.

Name: Gyula Kovacs, MD.

Contribution: This author helped conduct the study and write the manuscript.

Attestation: Gyula Kovacs has seen the original study data, reviewed the analysis of the data, and approved the final manuscript.

Name: Csaba Tömböly, MSc, PhD.

Contribution: This author helped conduct the study and write the manuscript.

Attestation: Csaba Tömböly has seen the original study data, reviewed the analysis of the data, and approved the final manuscript.

Name: György Benedek, MD, DSc.

Contribution: This author helped design the study and write the manuscript.

Attestation: György Benedek has seen the original study data and approved the final manuscript.

Name: Gyongyi Horvath, MD, DSc.

Contribution: This author helped design the study, analyze the data, and write the manuscript.
Attestation: Gyongyi Horvath has seen the original study data, reviewed the analysis of the data, approved the final manuscript, and is the author responsible for archiving the study files.

This manuscript was handled by: Quinn Hogan, MD.

\section{ACKNOWLEDGMENTS}

The authors thank Agnes Tandari for her technical assistance.

\section{REFERENCES}

1. Pertwee RG. Cannabinoid receptors and pain. Prog Neurobiol 2001;63:569-611

2. Agarwal N, Pacher P, Tegeder I, Amaya F, Constantin CE, Brenner GJ, Rubino T, Michalski CW, Marsicano G, Monory K, Mackie K, Marian C, Batkai S, Parolaro D, Fischer MJ, Reeh P, Kunos G, Kress M, Lutz B, Woolf CJ, Kuner R. Cannabinoids mediate analgesia largely via peripheral type 1 cannabinoid receptors in nociceptors. Nat Neurosci 2007;10:870-9

3. Lever IJ, Rice ASC. Cannabinoids and pain. Handb Exp Pharmacol 2007;177:265-306

4. Hohmann AG. Spinal and peripheral mechanisms of cannabinoid antinociception: behavioral, neurophysiological and neuroanatomical perspectives. Chem Phys Lipids 2002;121:173-90

5. Jhaveri MD, Sagar DR, Elmes SJR, Kendall DA, Chapman V. Cannabinoid CB2 receptor-mediated anti-nociception in models of acute and chronic pain. Mol Neurobiol 2007;36:26-35

6. Zhang J, Hoffert C, Vu HK, Groblewski T, Ahmad S, O'Donnell D. Induction of CB2 receptor expression in the rat spinal cord of neuropathic but not inflammatory chronic pain models. Eur J Neurosci 2003;17:2750-4

7. Romero-Sandoval A, Nutile-McMenemy N, DeLeo JA. Spinal microglial and perivascular cell cannabinoid receptor type 2 activation reduces behavioral hypersensitivity without tolerance after peripheral nerve injury. Anesthesiology 2008;108:722-34

8. Rioli V, Gozzo FC, Heimann AS, Linardi A, Krieger JE, Shida CS, Almeida PC, Hyslop S, Eberlin MN, Ferro ES. Novel natural peptide substrates for endopeptidase 24.15, neurolysin, and angiotensin-converting enzyme. J Biol Chem 2003;278: 8547-55

9. Lippton H, Lin B, Gumusel B, Witriol N, Wasserman A, Knight $M$. Hemopressin, a hemoglobin fragment, dilates the rat systemic vascular bed through release of nitric oxide. Peptides 2006;27:2284-8

10. Dodd GT, Mancini G, Lutz B, Luckman SM. The peptide hemopressin acts through CB1 cannabinoid receptors to reduce food intake in rats and mice. J Neurosci 2010;30:7369-76

11. Dale CS, Pagano RdL, Rioli V, Hyslop S, Giorgi R, Ferro ES. Antinociceptive action of hemopressin in experimental hyperalgesia. Peptides 2005;26:431-6

12. Heimann AS, Gomes L, Dale CS, Pagano RL, Gupta A, de Souza LL, Luchessi AD, Castro LM, Giorgi R, Rioli V, Ferro ES, Devi LA. Hemopressin is an inverse agonist of CB1 cannabinoid receptors. Proc Natl Acad Sci U S A 2007;104:20588-93

13. Devane WA, Hanus L, Breuer A, Pertwee RG, Stevenson LA, Griffin G, Gibson D, Mandelbaum A, Mechoulam R. Isolation and structure of a brain constituent that binds to the cannabinoid receptor. Science 1992;258:1946-9

14. Mechoulam R, Ben Shabat S, Hanus L, Ligumsky M, Kaminski NE, Schatz AR, Gopher A, Almog S, Martin BR, Compton DR. Identification of an endogenous 2-monoglyceride, present in canine gut, that binds to cannabinoid receptors. Biochem Pharmacol 1995;50:83-90

15. Hajos N, Ledent C, Freund TF. Novel cannabinoid-sensitive receptor mediates inhibition of glutamatergic synaptic transmission in the hippocampus. Neuroscience 2001;106:1-4

16. Oz M. Receptor-independent actions of cannabinoids on cell membranes: focus on endocannabinoids. Pharmacol Ther 2006;111:114-44

17. Tognetto M, Amadesi S, Harrison S, Creminon C, Trevisani M, Carreras M, Matera M, Geppetti P, Bianchi A. Anandamide excites central terminals of dorsal root ganglion neurons via vanilloid receptor-1 activation. J Neurosci 2001;21:1104-9 
18. van der Stelt $M$, Trevisani $M$, Vellani V, De Petrocellis L, Moriello AS, Campi B, McNaughton P, Geppetti P, Di Marzo $\mathrm{V}$. Anandamide acts as an intracellular messenger amplifying $\mathrm{Ca}^{2+}$ influx via TRPV1 channels. EMBO J 2005;24:3026-37

19. Di Marzo V, Blumberg PM, Szallasi A. Endovanilloid signaling in pain. Curr Opin Neurobiol 2002;12:372-9

20. van der Stelt M, Di Marzo V. Endovanilloids: putative endogenous ligands of transient receptor potential vanilloid 1 channels. Eur J Biochem 2004;271:1827-34

21. Zygmunt PM, Petersson J, Andersson DA, Chuang H, Sorgard M, Di Marzo V, Julius D, Högestätt ED. Vanilloid receptors on sensory nerves mediate the vasodilator action of anandamide. Nature 1999;400:452-7

22. Morisset V, Ahluwalia J, Nagy I, Urban L. Possible mechanisms of cannabinoid-induced antinociception in the spinal cord. Eur J Pharmacol 2001;429:93-100

23. Horvath G, Kekesi G, Nagy E, Benedek G. The role of TRPV1 receptors in the antinociceptive effect of anandamide at spinal level. Pain 2008;134:277-84

24. Ben Shabat S, Fride E, Sheskin T, Tamiri T, Rhee MH, Vogel Z, Bisogno T, De Petrocellis L, Di Marzo V, Mechoulam R. An entourage effect: inactive endogenous fatty acid glycerol esters enhance 2-arachidonoyl-glycerol cannabinoid activity. Eur J Pharmacol 1998;353:23-31

25. Desroches J, Guindon J, Lambert C, Beaulieu P. Modulation of the anti-nociceptive effects of 2-arachidonoyl glycerol by peripherally administered FAAH and MGL inhibitors in a neuropathic pain model. Br J Pharmacol 2008;155:913-24

26. Guindon J, Desroches J, Beaulieu P. The antinociceptive effects of intraplantar injections of 2-arachidonoyl glycerol are mediated by cannabinoid CB2 receptors. Br J Pharmacol 2007;150: 693-701

27. Mecs L, Tuboly G, Toth K, Nagy E, Nyari T, Benedek G, Horvath G. Peripheral antinociceptive effect of 2-arachidonoylglycerol and its interaction with endomorphin-1 in arthritic rat ankle joints. Clin Exp Pharmacol Physiol 2010;37:544-50

28. Yaksh TL, Rudy TA. Chronic catheterization of the spinal subarachnoid space. Physiol Behav 1976;17:1031-6

29. Dobos I, Toth K, Kekesi G, Joo G, Csullog E, Klimscha W, Benedek G, Horvath G. The significance of intrathecal catheter location in rats. Anesth Analg 2003;96:487-92

30. Mecs L, Tuboly G, Nagy E, Benedek G, Horvath G. Peripheral antinociceptive effects of endomorphin-1 and kynurenic acid in the rat inflamed joint model. Anesth Analg 2009;109:1297-304

31. Blais PA, Cote J, Morin J, Larouche A, Gendron G, Fortier A, Regoli D, Neugebauer W, Gobeil J. Hypotensive effects of hemopressin and bradykinin in rabbits, rats and mice: a comparative study. Peptides 2005;26:1317-22

32. Hama A, Sagen J. Activation of spinal and supraspinal cannabinoid-1 receptors leads to antinociception in a rat model of neuropathic spinal cord injury pain. Brain Res 2011;1412:44-54

33. Hama A, Sagen J. Centrally mediated antinociceptive effects of cannabinoid receptor ligands in rat models of nociception. Pharmacol Biochem Behav 2011;100:340-6

34. Guindon J, Hohmann AG. Cannabinoid CB2 receptors: a therapeutic target for the treatment of inflammatory and neuropathic pain. Br J Pharmacol 2007;153:319-34

35. Tuboly G, Mecs L, Benedek G, Horvath G. Antinociceptive interactions between anandamide and endomorphin-1 at the spinal level. Clin Exp Pharmacol Physiol 2009;36:400-5

36. Yaksh TL, Kokotos G, Svensson CI, Stephens D, Kokotos CG, Fitzsimmons B, Hadjipavlou-Litina D, Hua XY, Dennis EA Systemic and intrathecal effects of a novel series of phospholipase A2 inhibitors on hyperalgesia and spinal prostaglandin E2 release. J Pharmacol Exp Ther 2006;316:466-75
37. Oz M, Zhang L, Morales M. Endogenous cannabinoid, anandamide, acts as a noncompetitive inhibitor on $5-\mathrm{HT}_{3}$ receptor mediated responses in oocytes. Synapse 2002;46:150-6

38. Kim HI, Kim TH, Shin YK, Lee CS, Park M, Song JH. Anandamide suppression of $\mathrm{Na}^{+}$currents in rat dorsal root ganglion neurons. Brain Res 2005;1062:39-47

39. Hejazi N, Zhou C, Oz M, Sun H, Ye JH, Zhang L. Delta9tetrahydrocannabinol and endogenous cannabinoid anandamide directly potentiate the function of glycine receptors. Mol Pharmacol 2006;69:991-7

40. Lozovaya N, Yatsenko N, Beketov A, Tsintsadze T, Burnashev $\mathrm{N}$. Glycine receptors in CNS neurons as a target for nonretrograde action of cannabinoids. J Neurosci 2005;25:7499-506

41. Kondo S, Kondo H, Nakane S, Kodaka T, Tokumura A, Waku K, Sugiura T. 2-Arachidonoylglycerol, an endogenous cannabinoid receptor agonist: identification as one of the major species of monoacylglycerols in various rat tissues, and evidence for its generation through $\mathrm{Ca}^{2+}$-dependent and -independent mechanisms. FEBS Lett 1998;429:152-6

42. Kozak KR, Rowlinson SW, Marnett LJ. Oxygenation of the endocannabinoid, 2-arachidonylglycerol, to glyceryl prostaglandins by cyclooxygenase-2. J Biol Chem 2000;275:33744-9

43. Zhang J, Chen C. Endocannabinoid 2-arachidonoylglycerol protects neurons by limiting COX-2 elevation. J Biol Chem 2008;283:22601-11

44. Hohmann AG, Suplita RL, Bolton NM, Neely MH, Fegley D, Mangieri R, Krey JF, Walker JM, Holmes PV, Crystal JD, Duranti A, Tontini A, Mor M, Tarzia G, Piomelli D. An endocannabinoid mechanism for stress-induced analgesia. Nature 2005; $435: 1108-12$

45. Suplita RL II, Gutierrez T, Fegley D, Piomelli D, Hohmann AG. Endocannabinoids at the spinal level regulate, but do not mediate, nonopioid stress-induced analgesia. Neuropharmacology 2006;50:372-9

46. Hohmann AG, Suplita RL. Endocannabinoid mechanisms of pain modulation. AAPS J 2006;8:E693-708

47. Nyilas R, Gregg LC, Mackie K, Watanabe M, Zimmer A Hohmann AG, Katona I. Molecular architecture of endocannabinoid signaling at nociceptive synapses mediating analgesia. Eur J Neurosci 2009;29:1964-78

48. Hegyi Z, Kis G, Hollo K, Ledent C, Antal M. Neuronal and glial localization of the cannabinoid-1 receptor in the superficial spinal dorsal horn of the rodent spinal cord. Eur J Neurosci 2009;30:251-62

49. Bridges D, Rice ASC, Egertova M, Elphick MR, Winter J, Michael GJ. Localisation of cannabinoid receptor 1 in rat dorsal root ganglion using in situ hybridisation and immunohistochemistry. Neuroscience 2003;119:803-12

50. Sagar DR, Kelly S, Millns PJ, O'Shaughnessey CT, Kendall DA, Chapman V. Inhibitory effects of $\mathrm{CB} 1$ and $\mathrm{CB} 2$ receptor agonists on responses of DRG neurons and dorsal horn neurons in neuropathic rats. Eur J Neurosci 2005;22:371-9

51. Abram SE, Yi J, Fuchs A, Hogan QH. Permeability of injured and intact peripheral nerves and dorsal root ganglia. Anesthesiology 2006;105:146-53

52. Curto-Reyes V, Llames S, Hidalgo A, Menendez L, Baamonde A. Spinal and peripheral analgesic effects of the CB2 cannabinoid receptor agonist AM1241 in two models of bone cancerinduced pain. Br J Pharmacol 2010;160:561-73

53. Lever IJ, Malcangio M. CB1 receptor antagonist SR141716A increases capsaicin-evoked release of substance $\mathrm{P}$ from the adult mouse spinal cord. Br J Pharmacol 2002;135:21-4

54. Chapman V. The cannabinoid CB1 receptor antagonist, SR141716A, selectively facilitates nociceptive responses of dorsal horn neurones in the rat. Br J Pharmacol 1999;127:1765-7 